\title{
Removal of Congo Red Dye from Industrial Wastewater by Untreated Sawdust
}

\author{
Mohammad Shafiqul Alam, Rexona Khanom, Mohammad Arifur Rahman
}

Department of Chemistry, University of Dhaka, Dhaka, Bangladesh

Email address:

rexonakhanom@yahoo.com (R. Khanom)

\section{To cite this article:}

Mohammad Shafiqul Alam, Rexona Khanom, Mohammad Arifur Rahman. Removal of Congo Red Dye from Industrial Wastewater by Untreated Sawdust. American Journal of Environmental Protection. Vol. 4, No. 5, 2015, pp. 207-213. doi: 10.11648/j.ajep.20150405.12

\begin{abstract}
Dyes have widespread applications and exist in the effluents of various manufacturing and processing units; therefore, its discharge has a severe environmental impact. However, the complex aromatic molecular structures of dyes make them very stable, and as a result, more difficult to biodegrade. The objective of the present study is to explore the feasibility of using untreated sawdust in the removal of Congo Red dye from industrial wastewater. The adsorption study was carried out using different particle sizes of adsorbent $(90 \mu \mathrm{m}, 144 \mu \mathrm{m}$ and $355 \mu \mathrm{m})$, different $\mathrm{pH}$ values ranging from 5.0 to 11.0 along with different adsorbent amounts from 2.0 to $8.0 \mathrm{~g}$. Flow rate was also varied in the range of 0.3 to $0.7 \mathrm{~mL} / \mathrm{min}$. Optimization of volume required for saturation of untreated sawdust was investigated. Adsorption method showed the optimum removal of Congo Red dye under the following conditions: constant initial concentration of $10 \mathrm{mg} / \mathrm{L}$ dye solution, volume of $200.0 \mathrm{~mL}$, flow rate $0.3 \mathrm{~mL} / \mathrm{min}$, adsorbent amount $8.0 \mathrm{~g}$ and particle size of $90 \mu \mathrm{m}$. This effective removal method may provide a promising solution of removal of Congo Red dyes from textile wastewater in Bangladesh as well as other countries of the world.
\end{abstract}

Keywords: Removal of Congo Red (Dye), Industrial Waste Water, Untreated Sawdust

\section{Introduction}

Many manufacturing industries like dye, textile, paper and plastics industries use dyes in order to color their products and also consume substantial volumes of process water. As a result it generates a considerable amount of colored wastewater. Concern has been increased regarding the long term toxic effect of water containing these dissolved pollutants. The dye containing wastewater is usually released directly into the nearby drains, rivers, stagnant ponds or lagoons. Such wastewater disposal may cause damage to the quality of the receiving water bodies, the aquatic eco-system and the biodiversity of aquatic environment. The effluents produced by the industry containing high BOD and COD, suspended solids, toxic compounds and the color that is perceived by human eyes at very low concentration. The presence of small amount of dyes (less than $1 \mathrm{ppm}$ ) is highly visible and undesirable and needs to be removed before the wastewater can be discharged into the environment [1]. It is difficult to remove the dyes from the industrial waste, because dyes are not easily degradable [2].

Research to date includes numerous methods to remove dye that were extensively studied such as adsorption, coagulation, flocculation, ultra-filtration, nano-filtration, photo oxidation, adsorption onto activated carbon etc. But these methods are very expensive. At present physical, chemical and biological methods are generally used as a treatment process for removing dyes from textile wastewater. But all these methods are not cost-effective and environmental-friendly. As a result, an alternative environmental-friendly technology has become a necessity for the dye industry. Among these methods, adsorption is a widely used for dye removal from textile wastewater [3]. Granulated activated carbon (GAC) or powdered activated carbon (PAC) is commonly used for dye removal [4, 5]. However, they are expensive and the regeneration or disposal of it has several problems. Thus, the use of several low cost adsorbents has been studied by many researches. They have studied the feasibility of using low cost materials, such as waste orange peel [6]; lemon peel [7], banana pith, cotton waste, rice husk; bentonite clay; neem leaf powder; powdered activated sludge; perlite; bamboo dust, coconut shell, groundnut shell, rice husk, straw; duck weed and sewage sludge; algae, sawdust etc.

However, there are still challenges such as the maximum saturation of untreated sawdust. Over the last few years, 
adsorption has gained favor of importance in environment protection. Adsorbents are normally used for its environmental-friendly behavior, availability in nature and are very much cost effective. Untreated sawdust is largely composed of cellulose pectin; hemi-cellulose, lignin, etc. It can be used as an efficient and cost effective bio-adsorbent for removing dyes from industrial wastewater. In addition, untreated sawdust is alternative as a adsorbent for its abundance in nature, non-toxicity and bio-degradability. Generally, the most commonly used adsorbent for dye removal is activated carbon, because of its high surface area and thus capability for efficiently adsorbing a broad range of different types of adsorbates. However, its use is limited because of its high cost and the regeneration cost is also very high. Therefore, their use in wastewater treatment may be economically not feasible. There is a need to identify and study the adsorptive characteristics of low cost adsorbents [8]. The use of non-conventional adsorbents, particularly those that can be easily regenerated, to replace activated carbon in the removal of dye from wastewater has been addressed here. The removal of dyes from wastewater using adsorption process by untreated sawdust provides an alternative treatment. Adsorption of Congo Red dye (acid dye) was investigated by untreated sawdust.

Congo Red is one type of acid dyes. Acid dyes are brightest class of dyes [9] and are applied widely in industries. Congo Red is a heterocyclic aromatic chemical compound with molecular formula, $\mathrm{C}_{32} \mathrm{H}_{22} \mathrm{~N}_{6} \mathrm{Na}_{2} \mathrm{O}_{6} \mathrm{~S}_{2}$. Figure 1 shows the structure of Congo Red. Its chemical name is sodium salt of benzidinediazo-bis-1-naphthylamine-4-sulfonic acid.

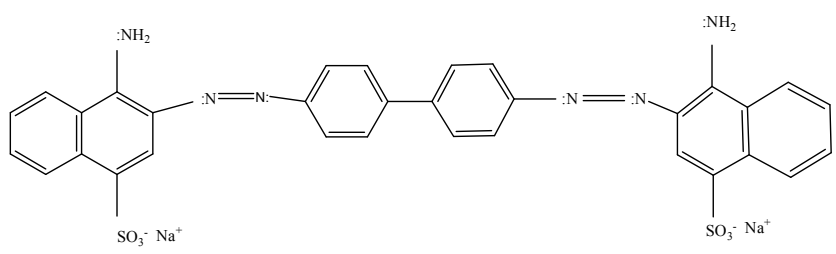

Figure 1. Structure of Congo red diazo dye.

Its formula is illustrated in Figure 1, and molecular weight is $696.66 \mathrm{~g} / \mathrm{mol}$. It is a secondary diazo dye having the color index number of 11313 .

Due to a color change from blue to red at $\mathrm{pH}$ 3.0-5.0, Congo Red can be used as a $\mathrm{pH}$ indicator. It has a strong affinity to cellulose fibers. However, the use of Congo Red in the cellulose industries (cotton textiles, wood pulp, and paper industry) has long been abandoned, primarily because of its tendency to change color when touched by sweaty fingers, to run, and because of its toxicity. It can be also used for diagnosis purpose [9].

The literature survey mentioned above suggests that many interesting questions can still be raised regarding average percentage removal of Congo Red and the correlations with the particle size of adsorbent, amount of adsorbent, flow rate, maximum volume of the Congo Red and $\mathrm{pH}$. Under fixed particle size, how does amount of adsorbent influences the percentage removal of the Congo Red dye? Under constant particle size and amount of adsorbents, how do flow rates govern the percentage removal of Congo Red dye? Under fixed particle size, amount of adsorbents, flow rate, how does maximum volume of the adsorbent affects the percentage removal of Congo Red dye? Does the percentage Congo Red dye depend on $\mathrm{pH}$ of the Congo Red solution? These are some of the issues that are addressed in this paper. Moreover, in the present investigation, approaches have been made to explore the removal of Congo Red with one waste material, untreated sawdust. The objective of the present study is to explore the feasibility of using untreated sawdust in the removal of Congo Red dye. The attractive features of the study: 1. Collection of adsorbent; 2. Preparation of adsorbent; 3. Optimization of different parameters such as amount of adsorbent amount, particle size of the adsorbent, flow rate, volume of Congo Red solution required for saturation of untreated sawdust, and $\mathrm{pH}$ of the Congo Red solution.

\section{Materials and Methods}

\subsection{Materials}

The following chemicals were used without further purification: Congo Red (CV) (Merck, Germany); Sodium hydroxide (Merck, Germany); 3. Hydrochloric acid (Analytical Reagent, Bangladesh).

\subsubsection{Collection and Preparation of Adsorbent}

Sawdust was collected from a Saw-mill of Kawran Bazar, Dhaka, Bangladesh. It was then soaked in de-ionized water for 12 hours. Then floating materials were discarded and dried in oven at $110^{\circ} \mathrm{C}$ temperature. It was then weighed and further dried until constant weight. After that it was ground into fine particles by grinding machine and sieved into different particle sizes. Particle sizes used for this study were $90 \mu \mathrm{m}, 140 \mu \mathrm{m}, 355 \mu \mathrm{m}$.

Then the adsorbent materials (for example $140 \mu \mathrm{m}$ ) were inserted into the column and de-ionized water was passed through the column until removal of dissolved coloring substances of adsorbent.

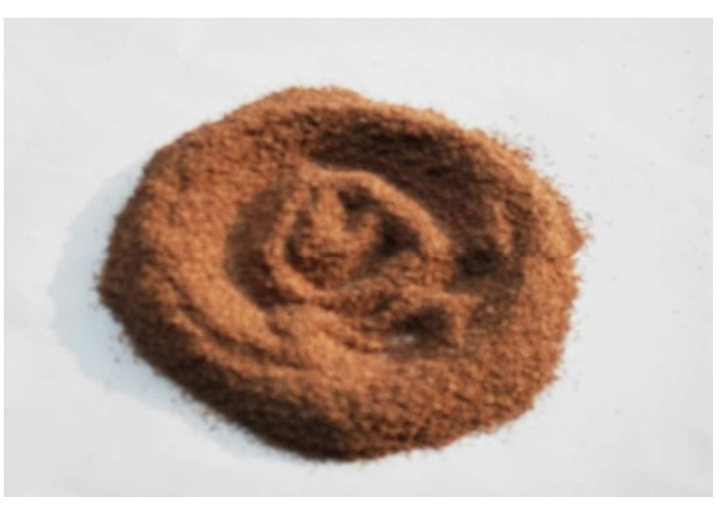

Figure 2. $140 \mu \mathrm{m}$-size Sawdust.

\subsubsection{Preparation of Congo Red Dye Stock Solution}

A dye stock solution of $1000 \mathrm{mg} / \mathrm{L}$ was prepared by dissolving $0.1 \mathrm{~g}$ of Congo Red dye in a $100 \mathrm{~mL}$ volumetric 
flask and diluted up to the mark by addition of de-ionized water. An aliquot of $1.0 \mathrm{~mL}$ of the stock solution was pipetted in a $100.0 \mathrm{~mL}$ volumetric flask and the volume was adjusted by addition of de-ionized water to prepare a solution of $10.0 \mathrm{mg} / \mathrm{L}$.

\subsubsection{Preparation of Standard Solutions Regarding Calibration Curve}

$2.0 \mathrm{mg} / \mathrm{L}, 4.0 \mathrm{mg} / \mathrm{L}, 6.0 \mathrm{mg} / \mathrm{L}$ and $8.0 \mathrm{mg} / \mathrm{L}$ Congo Red azo dye standard Solutions were prepared for the purpose of making the dye calibration curve.

\subsubsection{Preparation of Adsorption Column}

For the treatment of single adsorbent, glass wool was inserted firstly into the column, which acted as a support for the adsorbent. The soaked adsorbent with de-ionized water was poured into the column and water was then allowed to pass through the column. In this way, dissolved materials and colored substances were washed out from the adsorbent. Water was then drained out. Congo Red dye solution of 10.0 $\mathrm{mg} / \mathrm{L}$ concentration was then taken into the column and effluent was collected in a clean beaker.

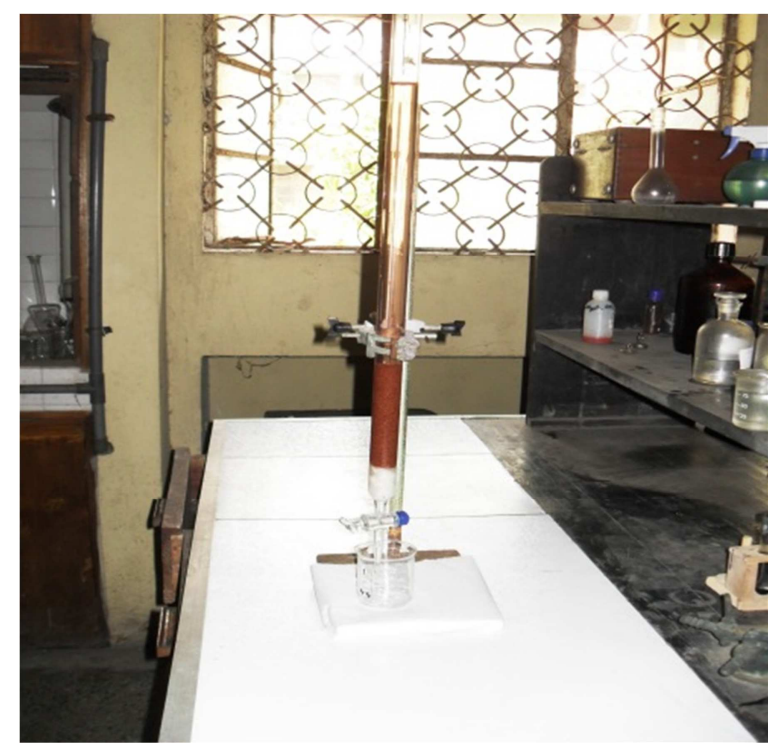

Figure 3. Experimental set up of column system.

\subsection{Methods}

\subsubsection{Determination of Maximum Absorbance $\left(\lambda_{\max }\right)$}

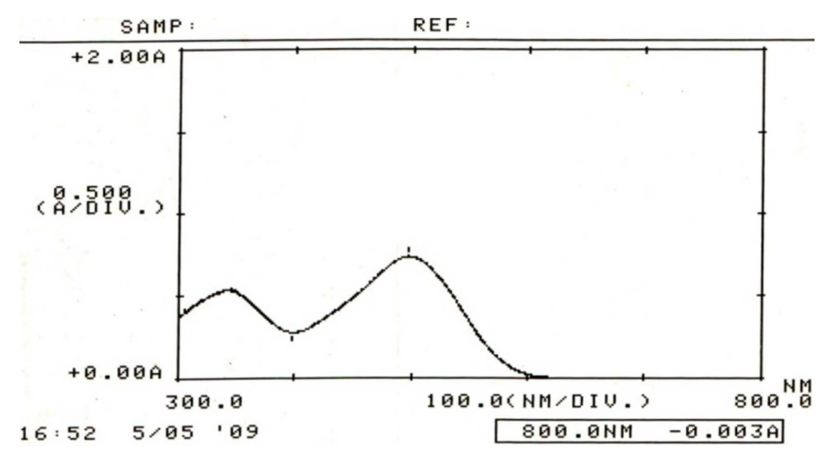

Figure 4. Determination of $\lambda_{\max }$ of Congo Red dye solution.
The maximum absorbance of Congo Red dye solution was measured by using UV-visible spectrophotometer (UV160A, Shimadzu, Japan) is given in Figure 4. Maximum absorbance for the solution of Congo Red was found at 497.0 $\mathrm{nm}$. All the absorbance measurements were carried out as the respective $\lambda_{\max }$ values to attain maximum sensitivity of the instrument.

\subsubsection{Measurement of Calibration Curve}

A calibration curve in UV-visible spectrometer was obtained by taking absorbance of the standard solution containing known concentration of the dye to be determined and by measuring the absorbance of each solution, there is a linear relationship between the absorbance and concentration is shown below in Figure 5.

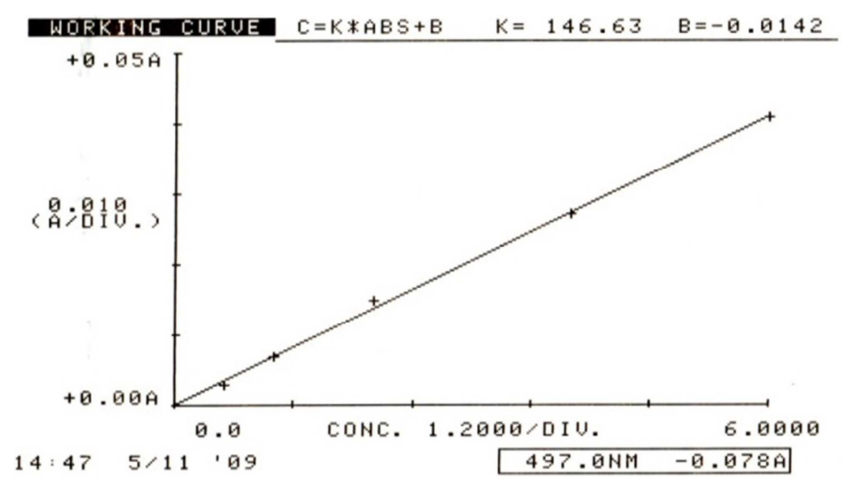

Figure 5. Calibration curve for different concentration of standard Congo Red dye solution.

The absorption of a monochromatic beam of light by a homogeneous absorbing system is described by BeerLambert law.

Modern absorption measuring instruments can usually display data as either transmittance, \%-transmittance, or absorbance. An unknown concentration of an analyte can be determined by measuring the amount of light that a sample absorbs and applying Beer-Lambert's law. If the absorptivity coefficient is known, the unknown concentration can be determined.

\subsubsection{Adsorption}

A molecule inside the bulk experiences cohesive forces of equal magnetic magnitude in all directions. The resultant cohesive they posses unbalanced or residual attractive force and hold adsorbed particles. The molecules on the surface are pulled downwards and sideways but no forces act on them above as shown in Figure 7. Therefore, they render them reactive towards liquid and gases. At the first available opportunity these surface atoms or molecules will try to satisfy the unstauration by 'capturing' other molecules atoms due to the tendency for the force energy of any surface to decrease [10-11]. If the valency requirement of the atoms on the surface satisfied, adsorption tends to take simply through the Van der Waals force attraction, resulting the physisorption. On the other hand, when the surface is unsatisfied, the adsorption takes place the chemical force for bond formation and termed as chemisorptions. 
Monolayer adsorption occurs due to single adsorption with adsorbent in chemisorptions and physisorption. But in some case of physisorption, multiplayer adsorption occurs due to lateral Van der Waals forces interaction.

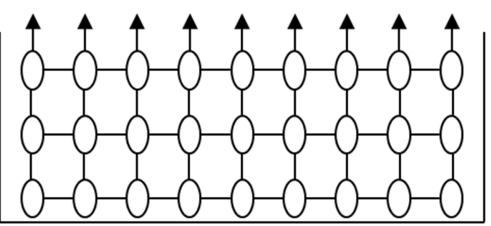

Figure 6. Unsaturation state of adsorbent.

\subsubsection{Adsorption Parameters Measurement}

\section{(i). Optimization of Particle Size, Amount of Adsorbent and}

\section{Flow Rate}

The effect of three different particle sizes such as $90 \mu \mathrm{m}$, $140 \mu \mathrm{m}$ and $355 \mu \mathrm{m}$ were investigated. Firstly, initial absorbance of 10 ppm Congo Red dye solution was measured 0.109 . Then, $100.0 \mathrm{~mL}$ of Congo Red dye solution of $10 \mathrm{ppm}$ was poured to the column of particle size 90.0 $\mu \mathrm{m}$. Five fractions were collected; volume of each fraction was $20.0 \mathrm{~mL}$. The absorbances were measured and consequently percentage removal of Congo Red dye was subjected to removal efficiency was calculated by using the following equation:

Percentage removal $=\left[\left(\mathrm{A}_{\mathrm{i}}-\mathrm{A}_{\mathrm{f}}\right) / \mathrm{A}_{\mathrm{i}}\right] \times 100,[\%]$

Where, $A_{i}=$ initial absorbance

$\mathrm{A}_{\mathrm{f}}=$ final absorbance

Percentage removal of Congo Red dye was varied from $95.41 \%$ to $88.23 \%$ with (e.g., particle size $90 \mu \mathrm{m}$ ) and average percentage removal of Congo Red was $91.33 \%$ was given in Table 1 and similarly with particle $140 \mu \mathrm{m}$ and 355 $\mu \mathrm{m}$ and average percentage removal of Congo Red dye were $87.53 \%$ and $84.43 \%$ respectively.

Table 1. Percentage removal of Congo Red dye for 90 um-size sawdust adsorbent.

\begin{tabular}{lll}
\hline Volume of eluent $(\mathbf{m L})$ & Percentage removal of Congo Red $(\%)$ & Average percentage removal of Congo Red (\%) \\
\hline 20 & 95.41 \\
20 & 93.24 \\
20 & 90.65 \\
20 & 89.10 \\
20 & 88.23 & \\
\hline
\end{tabular}

After selecting the optimized particle size, the different amounts of adsorbent were subjected to passage of $10 \mathrm{mg} / \mathrm{L}$ dye solution in the column with $0.3 \mathrm{~mL} / \mathrm{min}$. At this step, amount of adsorbent varied was within 2.0-8.0 g. The experimental column was packed with $8.0 \mathrm{~g}$ of sawdust of 90 $\mu \mathrm{m}$-size. $100.0 \mathrm{~mL}$ Congo Red dye solution of $10 \mathrm{ppm}$ was poured to the column. Five fractions were collected; volume of each fraction was $20.0 \mathrm{~mL}$. It was observed that the percentage removal of Congo Red dye was varied from $95.17 \%$ to $92.11 \%$ and average percentage removal of Congo Red was $94.43 \%$ was shown in Table 2. Similar manner observed with $2.0 \mathrm{~g}, 4.0 \mathrm{~g}$, and $6.0 \mathrm{~g}$ sawdust and thus average percentage removal of Congo Red were $86.1 \%$, $91.3 \%$ and $93.5 \%$ respectively.

Table 2. Percentage removal of Congo Red dye.

\begin{tabular}{|c|c|c|}
\hline Volume of Eluent (mL) & Percentage removal of Congo Red (\%) & Average percentage removal of Congo Red (\%) \\
\hline 20 & 95.17 & \\
\hline 20 & 95.17 & \\
\hline 20 & 95.17 & 94.43 \\
\hline 20 & 94.55 & \\
\hline 20 & 92.11 & \\
\hline
\end{tabular}

Table 3. Percentage removal of Congo Red azo dye for $0.5 \mathrm{~mL} / \mathrm{min}$.

\begin{tabular}{lll}
\hline Volume of Eluent $(\mathbf{m L})$ & Percentage removal of Congo Red $(\mathbf{m L})$ & Average percentage removal Congo Red $(\mathbf{m L})$ \\
\hline 20 & 96.33 & \\
20 & 96.33 & 89.27 \\
20 & 90.82 & \\
20 & 82.57 & \\
20 & 80.73 & \\
\hline
\end{tabular}

Then the influence of flow rate within the range of $0.3-$ $0.7 \mathrm{~mL} / \mathrm{min}$ on the adsorption process was studied using the optimized particle size and amount of adsorbent. It was observed that absorbances were varied and percentage removal of Congo Red dye was varied from $95.17 \%$ to $92.11 \%$ with flow rate $0.3 \mathrm{mg} / \mathrm{L}$ and average percentage removal of Congo Red was $94.43 \%$. Secondly, it was observed that the percentage removal of Congo Red dye was varied from $96.33 \%$ to $82.57 \%$ with flow rate $0.5 \mathrm{mg} / \mathrm{L}$ and average percentage removal of Congo Red was $89.27 \%$ depicted in Table 3. Similarly with $0.7 \mathrm{~mL} / \mathrm{min}$ flow rate and average percentage removal of Congo Red was $79.12 \%$.

\section{(ii). Optimization of Volume Required for Maximum Saturation of Untreated Sawdust and $\mathrm{pH}$}

The different volume of dye solution in the range of $20.0-$ $300.0 \mathrm{~mL}$ was then injected into the column to study its influence on adsorption. The experimental column was packed with $8.0 \mathrm{~g}$ of sawdust of $90 \mu \mathrm{m}$-size. $300.0 \mathrm{~mL}$ 
Congo Red dye solution of $10 \mathrm{ppm}$ was poured to the column. Twelve fractions were collected with flow rate 0.3 $\mathrm{mL} / \mathrm{min}$; volume of each fraction was $20.0 \mathrm{~mL}$. It was observed that sawdust was saturated after eluting $200.0 \mathrm{~mL}$, displayed in Table 4.

Table 4. Required volume until saturated removal efficiency of Congo Red dye.

\begin{tabular}{lll}
\hline Volume of Eluent $(\mathbf{m L})$ & Percentage removal of Congo Red (\%) & required volume for saturation of sawdust (mL) \\
\hline 20 & 95.57 & \\
20 & 92.03 \\
20 & 89.38 & \\
20 & 83.18 & \\
20 & 80.53 & 200.0 \\
20 & 76.10 & \\
20 & 69.91 & \\
20 & 61.94 & \\
20 & 48.67 & \\
20 & 44.24 & \\
20 & 44.24 & \\
\hline
\end{tabular}

And initial pH of solution was adjusted to 5, 7, 9 and 11 at optimum condition of particle size, adsorbent amount, flow rate, and volume for saturation of sawdust. It was observed that absorbances were varied and the percentage removal of Congo Red dye was varied from $97.92 \%$ to $95.50 \%$ with $\mathrm{pH}$
5.0 and average percentage removal of Congo Red was $96.0 \%$, inserted below in Table 5. Similarly, for the $\mathrm{pH}$ value $7.0,9.0,11.0$, average percentage removal of Congo Red was $92.50 \%, 80.0 \%$ and $63.52 \%$ respectively.

Table 5. Determination of percentage removal of Congo Red for pH 5.0.

\begin{tabular}{lll}
\hline Volume of eluent $(\mathbf{m L})$ & Percentage removal of Congo Red (\%) & Average percentage removal of Congo Red (\%) \\
\hline 20 & 97.92 \\
20 & 96.89 & \\
20 & 96.10 & 96.00 \\
20 & 95.70 \\
20 & 95.50 & \\
\hline
\end{tabular}

\section{Results and Discussion}

\subsection{Optimization of Particle Size, Amount of Adsorbent and Flow Rate}

The plot of percentage removal of Congo Red against particle size is depicted in Figure 8.

Figure refers that removal efficiency of adsorbent for Congo Red decreased with increasing particle size. Highest removal was observed with $90 \mu \mathrm{m}$-size untreated sawdust. Therefore, particle size $90 \mu \mathrm{m}$-size was chosen for next experiments. This phenomenon was probably due to the fact that, with the decrease of particle size, the surface areas of the adsorbent was increased, which provided greater number of adsorption sites for Congo Red to adsorb onto adsorbent.

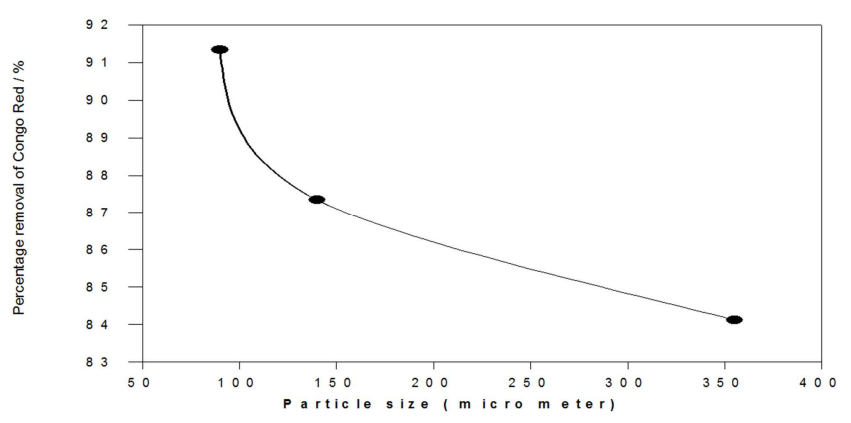

Figure 7. Optimization of particle size for the removal of Congo Red dye by adsorption.
Figure 9 which shows that removal efficiency increased with increasing amount of adsorbent. The rise in removal efficiency is due to increase in adsorption sites with increase in amount of adsorbent. It also shows that highest removal efficiency was exhibited by $8.0 \mathrm{~g}$ untreated sawdust $(94.43 \%)$. Consequently, $8.0 \mathrm{~g}$ untreated sawdust of $9 \mu \mathrm{m}$-size was selected for further study.

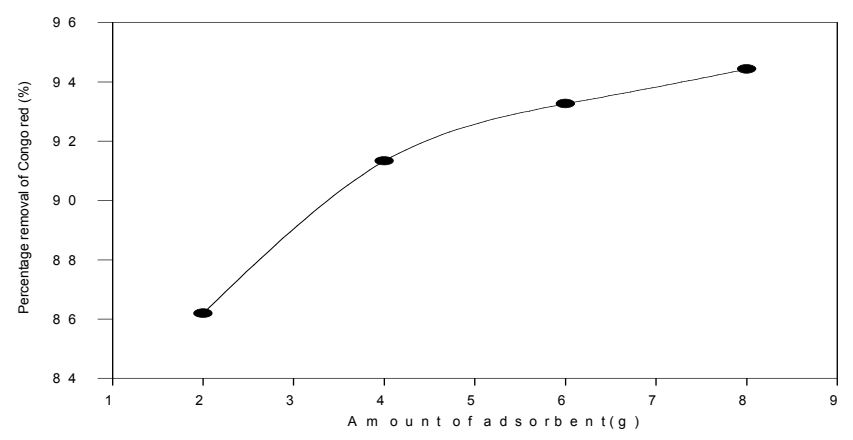

Figure 8. Optimization of amount of adsorbent (in ' $g$ ') on the removal of Congo red by adsorption.

The influence of the treatment flow rate on the removal of Congo Red is addressed in Figure 10. According to the figure 10, removal efficiency decreased with increasing flow rate. In general, $94.43 \%$ of Congo Red was removed at flow rate $0.3 \mathrm{~mL} / \mathrm{min}$. Higher removal of dye at slower flow rate was due to the fact that, when the flow rate was slow, Congo Red in the sample solution got more contact time with the active 
surface of the adsorbent. As a result, flow rate $0.3 \mathrm{~mL} / \mathrm{min}$ was chosen for the next experiments.

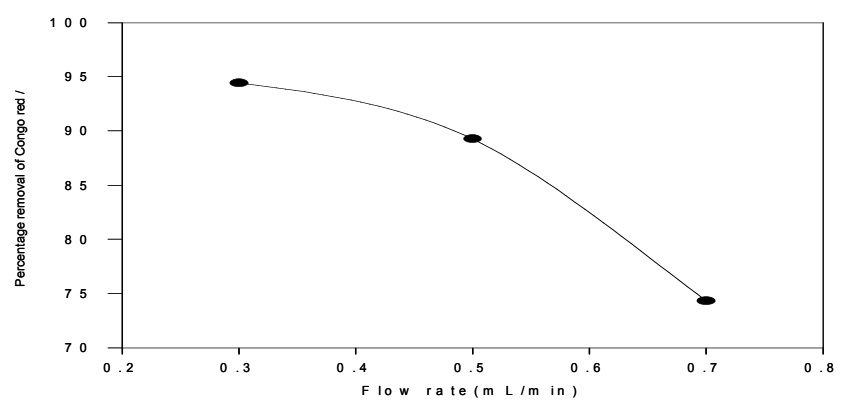

Figure 9. Optimization of flow rate on the removal Congo Red dye by adsorption.

\subsection{Optimization of Maximum Volume for Saturation of Adsorbent and $\mathrm{pH}$}

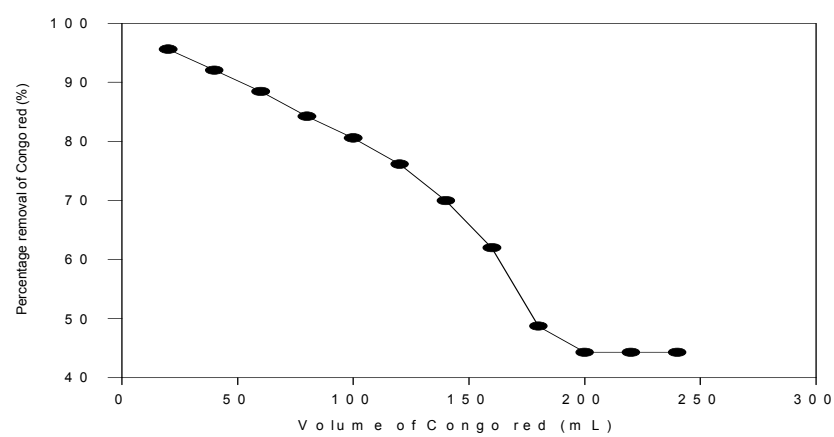

Figure 10. Optimization of maximum volume for saturation of adsorbent on the removal of Congo Red.

The effect of the volume on the removal of Congo Red dye is given in Figure 11. The figure shows that removal efficiency decreased with increasing of volume. At a stage of increasing volume, the removal efficiency attained saturation because there was no surface active site to adsorb dye molecule. When volume is $200.0 \mathrm{~mL}$, saturation value was obtained. The volume fixed for saturation was $200.0 \mathrm{~mL}$.

The consequence of $\mathrm{pH}$ on the removal of Congo Red in the presence of adsorbent is shown in Figure 12. Figure shows that as the $\mathrm{pH}$ increases, the removal of dye from the solution decreased. The decreasing trend of removal of the Congo Red with increasing $\mathrm{pH}$ was dependent of the nature of the adsorbent. Adsorption was the highest for $\mathrm{pH}$ 5.0. So, this $\mathrm{pH}$ was selected further study.

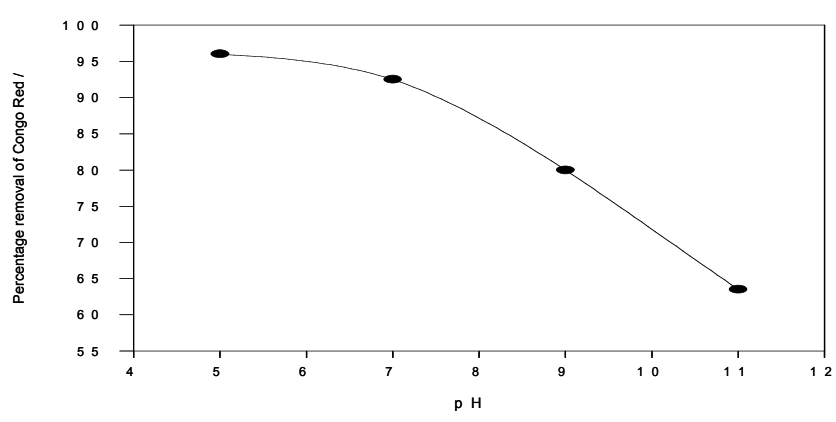

Figure 11. Optimization of pH on the removal of Congo Red by adsorption.

\subsection{Effect of $\mathrm{pH}$ on the Adsorption}

Surface charge of adsorbent is dependent on the $\mathrm{pH}$ and in some cases structure of the adsorbates species also depends on the $\mathrm{pH}$ of the solution. Hence the amount of adsorption and even the mechanism of the adsorption may be affected by the $\mathrm{pH}$ of the dye solution. So, $\mathrm{pH}$ dependency also gives information about the mechanism of adsorption. The effect of $\mathrm{pH}$ on adsorption by sawdust can be explained on the basis of point of zero charge $\mathrm{pH}_{\mathrm{pzc}}$, at which adsorbent is neutral, while beyond this the material becomes either positively or negatively charged. $\mathrm{The}_{\mathrm{pH}}$ value for sawdust $=5.2 \pm 0.2[12]$. Below the zero point charge that is at low $\mathrm{pH}$ with an increasing of the concentration of the $\mathrm{H}^{+}$ion in dye solution, the $\mathrm{OH}$ groups of the surface of sawdust would get neutralize by protonation. That is at lower $\mathrm{pH}$, the presence of more $\mathrm{H}^{+}$ions increases the number of positively charged adsorbent sites and the increase in the number of positively charged surface sites probably favor the adsorption of negatively charged dye (Congo Red dye). Because, there is an electrostatic attraction increase with decreasing of $\mathrm{pH}$, thus resulting an increase of dye adsorption.

Above point of zero charge that is at higher $\mathrm{pH}$ with an increasing concentration of the $\mathrm{OH}^{-}$ion in dye solution, the surface $\mathrm{OH}^{-}$groups increases. Consequently the negative charge density would be located more on the dye molecule and this accounts for the lower dye uptake on increasing negatively charged surface sites, because electrostatic repulsion increases with increasing $\mathrm{pH}$.

\section{Conclusions}

Dyes are generally present in the effluents of textile industries. These are distributed in soils, aquatic environment and are known to be a source of environmental contamination. So, the necessity demands to focus the attention on techniques leading to complete removal of dye molecules. The removal of Congo Red from industrial wastewater using untreated sawdust has been investigated under different experimental conditions. The adsorption of Congo Red was found to be dependent on the adsorbent particle size, amount of adsorbent, flow rate of effluent and volume of dye solution. The uptake of Congo Red was greatly affected by the dye solution $\mathrm{pH}$. The optimized conditions can be applied for the design and fabrication of an economically favorable treatment process.

\section{Acknowledgments}

The author thanks Department of Chemistry, Dhaka University, Bangladesh for the financial support to carry out this work and also thank Dr. A. M. Shafiqul Alam, M.Sc. (Dhaka), M.S. in Anal chem. (Lyon, France), D.Sc. (Lyon, France), C. Chem., FRSC (London), Professor, Department of chemistry, University of Dhaka and Dr. M. Arifur Rahman, M.Sc. (Dhaka), Ph.D (Mie University, Japan), 
lecturer, Department of chemistry, University of Dhaka for supervision, instrumental support and encouragement. The author gratefully acknowledges "Analytical Laboratory" for the use of UV-Visible Spectrophotometer.

\section{References}

[1] Vandevivere P. C., Bianchi R, Verstreate, W. (1998), Treatment and reuse of wastewater from the textile WetProcessing Industry: review of emerging technologies. J. Chem. Technol. Biotechnol, 72, 289-302.

[2] Isik M. and Sponza D. T. (2005), A batch study for assessing the inhibition effects of Direct Yellow 12 in a Mixed methanogenic culture. Process Bio-Chemistry, 40 (3-4-40), 1053-1062.

[3] Alzaydien A. S., Adsorption of Methylene Blue from Aqueous Solution on a Low-cost Natural Jordanian Tripoli, American Journal of Environmental Science, 2009, vol. 5, No. 1, 197208.

[4] Walker G. M. and Weatherly L. R. (1998), Fixed bed adsorption of acid dyes onto activated carbon, Environmental Pollution, vol. 99, No.1, 133-136.

[5] Chem Jia-Ming and Wu Chia-Yuan (2001), Desorption of dye from activated carbon beds: effects of temperature, $\mathrm{pH}$ and alcohol, Water Research, 2001, vol. 35, No.17, 4159-4165.
[6] Kumar K. V. (2007), Optimum sorption isotherm by linear and non-linear methods for malachite green onto lemon peel, Dyes and Pigments, 2007, vol. 74, No.3, 595-597.

[7] Ajay Meena. Chitra Rajagopal, Comparative Studies on Adsorptive Removal of Chromium from Contaminated water Using Different Adsorbents, Indian Journal of Chemical Technology, ISSN: 0971-457X, Jan. 2003, Vol. 10, No.1, pp.72-78.

[8] Pappic S., Koprivanac N., Metes A. (2000), Optimizing polymer induced flocculation process to remove the active dyes from wastewater, Environmental Technology, 2000, 21, 97-105.

[9] Steensma D. P., Congo red: out of Africa?, Archives of Pathology and Laboratory Medicine, 2001 125(2), 250-252.

[10] Haque M. and Nawab A. (1974), Principles of Physical chemistry, $3^{\text {rd }}$ Edition, p 371, Dhaka, Student Publications, Bangladesh.

[11] Glastone S. (1974), Test Book of Physical Chemistry, $3^{\text {rd }}$ Edition, Pub. Maxmillian Student Editions p 1194.

[12] F. A. Batzias, D. K. Sidiras, Simulation of dye adsorption by beech sawdust as affected by $\mathrm{pH}$, Journal of Hazardous Materials, 2007, 141(3) 668-679. 